\title{
Comamonas testosteroni: An Unusual Bacteria Associated with Acute Appendicitis
}

Dear Editor,

Comamonas testosteroni has been rarely observed as an infectious agent in clinical practice. The organism has the low virulence potency and infrequently causes human disease. Comamonas species (previously classified within the Pseudomonas group) have widespread environmental distribution and also survive for a long time in hospital environments (1, 2). We present a previously healthy adolescent with localised peritonitis as a complication of perforated appendicitis associated with polymicrobial aetiology including $C$. testosteroni.

A 16-year-old male presented to our hospital with acute abdominal pain, vomiting, and constipation for 3 days. On physical examination, abdominal tenderness, guarding and rebound tenderness at the right iliac fossa, and absence of bowel sounds were detected. The remaining examination findings were unremarkable. Laboratory findings were as follows: white cell count was $24.2 \times 10^{3} / \mu \mathrm{L}$ (normal range: $5.1-15.5$ ); haemoglobin $16.1 \mathrm{~g} /$ $\mathrm{dL}$; platelet count $234 \times 10^{3} / \mu \mathrm{L}$; and C-reactive protein $189 \mathrm{mg} / \mathrm{L}$ (normal range: 0-8). Serum electrolyte levels, renal and liver function tests were in normal ranges. Abdominal ultrasonography revealed a tubular structure compatible with appendicitis. The presence of an appendicolith was detected. Exploration of the abdominal cavity showed an inflamed and perforated appendix and several adhesions around the terminal ileum. The appendix was removed and the adhesions were dissected. Saline peritoneal lavage was performed. The patient was treated with intravenous amicasin, ampicillin, and clindamycin. He was discharged from the hospital on the fifth day after the operation. The culture of peritoneal fluid revealed $C$. testosteroni, Escherichia coli, and Enterococcus spp. The isolated C. testosteroni was sensitive to ampicillin, ampicillin-sulbactam, ceftazidime, cefazolin, gentamicin, amicasin, ciprofloxacin, imipenem, and piperacillin and was resistant to ceftriaxone, cefuroxime, and trimethoprim/sulfamethoxazole.

Comamonas species are aerobic, Gram-negative, motile, pink-pigmented, oxidase-positive bacilli that grow well on routine bacteriological media. This group consists of four species: Comamonas terrigena, $C$. testosteroni, Comamonas denitrificans, and Comamonas nitrativorans. The organisms have low virulence potency and infrequently cause human disease (1). C. testosteroni is the most common pathogen of the genus. This organism is called 'testosteroni' because it can grow on media containing testosterone as a sole carbon source $(2,3)$

The authors recently collected all reported cases relating to C. testosteroni since 1987. C. testosteroni had been iso- lated from the bloodstream in 13 cases, abdominal cavity in 10 cases, cerebrospinal fluid in three cases, urine in one case, cord blood in one case, vitreous sample in one case, and one from the infection site of an animal bite. Among the 10 cases with abdominal cavity infection, $C$. testosteroni had been isolated from the peritoneal cavity in eight cases, abscess material in one case, and appendix in one case. Any cases of peritoneal infection had predisposing factor. In two cases, perforated appendicitis or alcoholic cirrhosis was identified as the predisposing factor $(2,4)$. C. testosteroni had also been reported among the pathogens isolated from respiratory secretions of cystic fibrosis patients (5). C. testosteroni abdominal infections occur most often in association with perforation of the appendix; therefore, these infections are commonly polymicrobial. Our patient also had a polymicrobial aetiology.

Among the 33 patients with $C$. testosteroni infections including the present case, four patients died. All of the patients who died had underlying conditions. Apart from these patients, $C$. testosteroni-related infections responded well to antibiotic treatment $(2,3,6)$. None of the patients with $C$. testosteroni abdominal infections died. As in previously reported cases, our patient recovered uneventfully by force of surgical intervention and antibiotic therapy. Most of the reported $C$. testosteroni isolates are susceptible to aminoglycosides, fluoroquinolones, carbapenems, piperacillin-tazobactam, most cephalosporins, and trimethoprim-sulfamethoxazole $(3,4,7)$.

The patient presented localised peritonitis as a complication of perforated appendicitis due to a polymicrobial aetiology, including a rare human pathogen. We concluded that $C$. testosteroni peritonitis originating from perforated appendicitis might involve a healthy adolescent without known environmental exposure. Because the pathogen was susceptible to the empirical antibiotic treatment of appendicitis and timely surgical intervention, an uneventful outcome was achieved.

Gülsüm İclal Bayhan', Gönül Tanır ${ }^{1}$, İbrahim Karaman², Şengül Özkan ${ }^{3}$

${ }^{1}$ Department of Pediatric Infectious Diseases, Dr. Sami Ulus Maternity, Children's Health and Disease Research and Training Hospital, Ankara, Turkey

${ }^{2}$ Department of Pediatric Surgery, Dr. Sami Ulus Maternity, Children's Health and Disease Research and Training Hospital, Ankara, Turkey

${ }^{3}$ Department of Infectious Diseases and Clinical Microbiology, Dr. Sami Ulus Maternity, Children's Health and Disease Research and Training Hospital, Ankara, Turkey 


\section{Ethics Committee Approval: N/A}

Informed Consent: Written informed consent was obtained from the patient.

Peer-review: Externally peer-reviewed.

Author contributions: Concept - Ş.Ö.; Design - G.I.B., G.T.; Supervision - G.T., i.K.; Resource - G.i.B., G.T.; Materials - Ş.Ö.; Data Collection\&/or Processing - Ş.Ö.; Analysis\&/or Interpretation - i.K.; Literature Search - G.T., I.K., Ş.Ö.; Writing - G.i.B., i.B., I.K.; Critical Reviews - G.I.B., G.T.

Conflict of Interest: No conflict of interest was declared by the authors.

Financial Disclosure: The authors declared that this report received no financial support.

\section{References}

1. Willems A, De Vos P. Comamonas. In: Dworkin M, Falkow S, Schleifer KH, Stackebrandt E, editors. The Prokaryotes. Singapore;2006:723-736. [CrossRef]
2. Farshad S, Norouzi F, Aminshahidi M, Heidari B, Alborzi A. Two cases of bacteremia due to an unusual pathogen, Comamonas testosteroni in Iran and a review literature. J Infect Dev Ctries 2012;6:521-5.

3. Tsui TL, Tsao SM, Liu KS, Chen TY, Wang YL, Teng YH, et al. Comamonas testosteroni infection in Taiwan:Reported two cases and literature review. J Microbiol Immunol Infect 2011;12;44:67-71. [CrossRef]

4. Arda B, Aydemir S, Yamazhan T, Hassan A, Tünger A, Serter D. Comamonas testosteroni meningitis in a patient with recurrent cholesteatoma. APMIS 2003;111:474-6. [CrossRef]

5. Coenye T, Goris J, Spilker T, Vandamme P, LiPuma JJ. Characterization of unusual bacteria isolated from respiratory secretions of cystic fibrosis patients and description of Inquilinus limosus gen. nov., sp. nov. J Clin Microbiol 2002;40:2062-9. [CrossRef]

6. Jin L, Perper JA, Cina SJ. Comamonas testosteroni meningitis in a homeless man. J Forensic Sci 2008;53:1198-9. [CrossRef]

7. Brady TB, Marcon MJ. Less commonly encountered nonenteric Gram-negative bacilli. In: Long SS, Pickering LK, Prober CG editors. Principles and Practise of Pediatric Infectious Diseases. Churchill Livingstone 2008:828-831. [CrossRef] 